\title{
Eficácia acaricida do óleo de citronela contra o Rhipicephalus (Boophilus) microplus
}

\author{
Acaricidal efficacy against "Rhipicephalus (Boophilus) microplus" of citronella oil
}

\author{
AGNOLIN, Carlos Alberto $^{1 *}$; OLIVO, Clair Jorge ${ }^{2}$; PARRA, Carla Lieda Cezimbra ${ }^{1}$; \\ AGUIRRE, Priscila Flores ${ }^{1}$; de BEM, Claudia Marques ${ }^{1}$; ZENI, Diego ${ }^{1}$; MOREL, \\ Ademir Farias ${ }^{3}$
}

\author{
${ }^{1}$ Universidade Federal de Santa Maria, Programa de Pós-Graduação em Zootecnia, Santa Maria, Rio \\ Grande do Sul, Brasil. \\ ${ }^{2}$ Universidade Federal de Santa Maria, Centro de Ciências Rurais, Departamento de Zootecnia, Santa \\ Maria, Rio grande do Sul, Brasil. \\ ${ }^{3}$ Universidade Federal de Santa Maria, Departamento de Química, Centro de Ciências Naturais e Exatas , \\ Santa Maria, Rio grande do Sul, Brasil. \\ *Endereço para correspondência: caiozoot2002@yahoo.com.br
}

\section{RESUMO}

O Rhipicephalus (Boophilus) microplus é o carrapato bovino mais importante no Brasil. Para o controle do carrapato, vários estudos com plantas têm sido desenvolvidos numa tentativa de encontrar extratos com propriedades acaricidas. Esta pesquisa foi conduzida com o objetivo de avaliar o efeito in vitro e in vivo do óleo de citronela (Cymbopogon winterianus Jowitt) sobre o carrapato bovino. $\mathrm{Na}$ experimentação in vitro foi utilizado o grupo controle negativo e oito concentrações de óleo de citronela e óleo mineral $(0,5 ; 1 ; 2 ; 5 ; 10 ; 20 ; 50 ; 100 \%)$, em fêmeas ingurgitadas de carrapatos. A eficácia carrapaticida para o óleo de citronela foi de $0 ; 34,5 ; 43 ; 48 ; 82$; 99; 99; 100 e $100 \%$, respectivamente; para o óleo mineral foram observados resultados irregulares na eficácia acaricida. Para a experimentação in vivo foram constituídos três grupos: controle negativo; óleo de citronela a 8,6\% - nível estimado mediante análise de regressão, correspondendo a $95 \%$ de eficácia acaricida da pesquisa in vitro e amitraz a $0,025 \%$, com dezoito vacas da raça Holandesa. Antes, média dos dias $-3,-2,-1$ e após a aplicação do produto, 1, 2, 3, 5, 7, 10, 14 e 21 dias, foram contadas fêmeas ingurgitadas de carrapato. $\mathrm{Na} 1^{\mathrm{a}} \mathrm{e}$ na $2^{\mathrm{a}}$ ordenha após a aplicação dos tratamentos, foram avaliadas variáveis físiológicas (controle negativo $\mathrm{x}$ tratamento fitoterápico). A eficácia carrapaticida foi de $0 ; 91,3$ e $60 \%$, respectivamente, 21 dias após o tratamento. Os valores das variáveis fisiológicas avaliadas foram similares entre os tratamentos.

Palavras-chave: acaricida, carrapato bovino, Cymbopogon winterianus, fitoterápico, vacas em lactação

\section{SUMMARY}

The Rhipicephalus (Boophilus) microplus is the most important cattle tick in Brazil. For the ticks control, various studies on plants have been developed in an attempt to find extracts with acaricidal properties. This research was aimed at evaluating in vitro and in vivo effects of citronella (Cymbopogon winterianus Jowitt) oil on cattle ticks. Negative control group and eight concentrations of citronella oil and mineral oil $(0.5 ; 1 ; 2 ; 5 ; 10 ; 20 ; 50 ; 100 \%)$, were used on in vitro trials with engorged female ticks. The efficacy against cattle ticks was $0 ; 34.5 ; 43 ; 48 ; 82$; 99; 99; 100 and $100 \%$, respectively, for citronella oil. For mineral oil contradictory results of acaricidal efficacy were observed. At the in vivo trial eighteen Holstein cows were allocated to three groups: negative control; citronella oil at $8.6 \%$ level estimated by regression analysis, accounting for $95 \%$ efficacy against ticks on in vitro trial and amitraz at $0.025 \%$. Engorged female ticks were counted before, mean of days $-3,-2,-1$, and after treatment, 1, 2, 3, 5, 7, 10, 14 and 21 days. On the $1^{\text {st }}$ and $2^{\text {nd }}$ milked after treatments, physiologic variables were evaluate (negative control $x$ phytotherapic treatment). The efficacy against tick was $0 ; 91.3$ and $60 \%$, respectively, at 21 days after treatment. Similar results were found with physiologic variables between treatments.

Keywords: acaricide, cattle tick, Cymbopogon winterianus, lactating dairy cows, phytotherapic 


\section{INTRODUÇÃO}

O parasitismo por carrapato é um dos maiores problemas verificados na atividade leiteira. O carrapato, Rhipicephalus (Boophilus) microplus, provoca perdas econômicas significativas em áreas tropicais e subtropicais do mundo, de dezenas de bilhões de dólares por ano, em todo o mundo. No Brasil, a infestação por carrapatos de bovinos é uma das principais causas da baixa produtividade da criação de gado (PARIZI et al., 2009). Dentre as alternativas para controlar o carrapato, destacam-se os acaricidas convencionais. Essa estratégia, no entanto, nem sempre é efetiva, pois, muitos agricultores fazem uso indiscriminado e de forma errônea desses produtos, havendo, assim, redução de sua eficácia (FURLONG et al., 2004), e possibilitando o desenvolvimento de resistência de cepas ao composto usado (GOMES et al., 2011; KLAFKE et al., 2006).

Agrega-se também a contaminação ambiental causada por essa estratégia e possíveis problemas de saúde pública, considerando que parte dos produtores não observa os períodos de carência dos produtos utilizados, implicando em muitos casos, na presença de resíduos na carne e no leite (HEIMERDINGER et al., 2006). Devido a esses problemas há uma tendência mundial para reduzir a utilização de acaricidas e inseticidas químicos tanto quanto possível (FARIAS et al., 2009), recomendando-se a busca por soluções alternativas para o controle do carrapato (PARIZI et al., 2009). Dentre elas destaca-se a utilização de fitoterápicos, devido a grande variabilidade de espécies de plantas existentes, o baixo custo e a fácil disponibilidade. Ressalta-se que normalmente os fitoterápicos apresentam baixa toxicidade aos mamíferos, lenta resistência parasitária e são biodegradáveis (CHUNGSAMARNYART \& JIWAJINDA, 1992), proporcionando, consequentemente, baixo impacto ambiental e redução de resíduos nos produtos de origem animal (CHAGAS, 2004).

Várias pesquisas conduzidas com óleo de citronela $(C$. nardus $)$ demonstraram sua ação como inseticida (AGNOLIN et al., 2010; MARTINS, 2006; OLIVO et al., 2008). Há, no entanto, poucos estudos que associam experimentações feitas em laboratório e in vivo, na mesma pesquisa, quanto à eficácia acaricida, bem como de possíveis efeitos do uso do produto sobre a fisiologia dos animais.

Assim, o objetivo do trabalho foi avaliar a eficácia do óleo de citronela como acaricida em carrapatos de bovinos, valendo-se de experimentações in vitro e in vivo, e verificando possíveis efeitos do produto nas variáveis fisiológicas dos animais.

\section{MATERIAL E MÉTODOS}

A citronela utilizada (Cymbopogon winterianus Jowitt) foi cultivada na mesorregião Noroeste do Rio Grande do Sul. O óleo foi extraído, da parte aérea de plantas frescas, na usina de extração de óleos essenciais por arraste a vapor no Polo Oleoquímico de Três Passos, da Universidade do Noroeste do estado do Rio Grande do Sul (UNIJUí), tendo apresentado rendimento de 0,7\%, aproximadamente. A análise cromatográfica do óleo foi realizada no Departamento de Química da Universidade Federal de Santa Maria (UFSM), apresentando, como princípios ativos mais importantes, o citronelal $(47,5 \%), \quad$ o geranial $(18,9 \%)$ e o 
citronelol $(10,7 \%)$. Outros compostos perfizeram $22,9 \%$.

Para os testes in vitro foram coletadas fêmeas ingurgitadas com comprimento superior a $8 \mathrm{~mm}$, retiradas de animais da raça Holandesa, naturalmente infestados, pertencentes ao Laboratório de Bovinocultura de Leite do Departamento de Zootecnia da Universidade Federal de Santa Maria.

Os tratamentos foram constituídos pelo grupo controle e diferentes concentrações do óleo de citronela $(0,5 ; 1 ; 2 ; 5 ; 10 ; 20$; 50 e 100\%). Para o grupo controle (testemunha, sem óleo) e para a complementação das demais soluções (até o nível de 50\%) usou-se água destilada. As fêmeas ingurgitadas foram colocadas aleatoriamente em grupos de 10 em cada placa de Petri, sendo usadas três placas/tratamento, submetidas ao teste de imersão de fêmeas ingurgitadas (DRUMMOND et al., 1973), realizado no Laboratório de Doenças Parasitárias da UFSM. O delineamento experimental utilizado foi $o$ inteiramente casualizado, com três repetições (placas de Petri). Também foram usadas as mesmas concentrações com óleo mineral $(75,68$ de hidrocarbonetos parafinados e 24,32\% de material inerte), diluído em água destilada, visando determinar um possível efeito acaricida da oleosidade.

O projeto experimental foi aprovado pelo Comitê de Ética e Biossegurança da UFSM pelo parecer 113/2011 sob o protocolo $\mathrm{n}^{\circ} 23081016073 / 2011$.

$\mathrm{O}$ experimento in vivo foi realizado no Laboratório de Bovinocultura de Leite (DZ, UFSM). Foram constituídos três grupos: amitraz, a $0,025 \%$ (grupo controle positivo), óleo de citronela a $8,6 \%$ e testemunha (grupo controle negativo). A opção pelo amitraz deveuse à eficácia in vitro de $98,2 \%$ no controle da cepa utilizada no presente experimento. Para a concentração com óleo de citronela, o nível utilizado de $8,6 \%$, teve como base os resultados da experimentação in vitro, sendo submetidos à análise de regressão polinomial, estimando-se um valor de 95\% de eficácia. O óleo de citronela utilizado foi o mesmo daquele utilizado na experimentação in vitro.

Nas avaliações foram utilizadas 18 vacas em lactação da raça Holandesa, do mesmo rebanho, com cerca de $521 \mathrm{~kg}$ de peso vivo e produção média de $21 \mathrm{~kg}$ de leite/vaca/dia. Os animais foram submetidos diariamente a duas ordenhas. A base da alimentação foi constituída de pastagens perenes de ciclo estival. A complementação alimentar foi feita com concentrado ( $18 \%$ PB) à razão de $4,5 \mathrm{~kg} / \mathrm{vaca} / \mathrm{dia}$, dividida entre as ordenhas da manhã e da tarde. Foram utilizadas seis vacas por tratamento, naturalmente infestadas por carrapato, que apresentavam, individualmente, no mínimo dez teleóginas (média de três dias consecutivos). O preparo das soluções e a aplicação foram feitos após a ordenha da tarde, utilizando-se de pulverizador costal. Para ambos os tratamentos, a quantidade de calda usada, foi de 4 litros/vaca.

Para as avaliações foram efetuadas contagens de carrapato, considerando-se os ínstares com tamanho entre $4,5 \mathrm{e}$ $8 \mathrm{~mm}$ de comprimento, na metade direita do corpo do animal, multiplicando-se o valor por dois para a obtenção da infestação total (WHARTON \& UTECH, 1970). As contagens foram feitas no $1^{\mathrm{o}}, 2^{\mathrm{o}}, 3^{\mathrm{o}}, 5^{\mathrm{o}}, 7^{\mathrm{o}}, 10^{\mathrm{o}}, 14^{\mathrm{o}}$ e $21^{\mathrm{o}}$ dia após a aplicação das soluções. Para calcular a eficácia do produto foi utilizada a fórmula descrita por Amaral (1993), sendo a eficácia $=\left[\left(\mathrm{N}^{\mathrm{o}}\right.\right.$ de carrapatos do grupo controle $-\mathrm{N}^{\mathrm{o}}$ de carrapatos do grupo tratado) / $\mathrm{N}^{\mathrm{o}} \mathrm{de}$ carrapatos do grupo controle] $* 100$. O delineamento experimental utilizado foi 
o inteiramente casualizado, com três tratamentos e seis repetições (vacas).

Às variáveis fisiológicas, foram aferidos antes e às 3; 6 e 24 horas após a aplicação dos tratamentos. As frequências cardíaca e respiratória foram verificadas mediante auscultação com estetoscópio. Para aferir as temperaturas de globo ocular e da superfície da pele utilizou-se equipamento com infravermelho (TI 890 Instron com resolução de 50x).

$\mathrm{O}$ delineamento experimental foi $\mathrm{O}$ inteiramente casualizado, com quatro repetições (vacas), sendo os tratamentos constituídos pelos grupos controle negativo e positivo (com produto químico à base de amitraz), além da solução com $8,6 \%$ de óleo de citronela, estimada a partir da análise de regressão, para controlar $95 \%$ do carrapato.

Para ambos os experimentos (in vitro e in vivo), os dados foram submetidos à análise de variância e as médias comparadas pelo teste de Tukey ou F (segundo a experimentação) ao nível de $5 \%$ de probabilidade do erro. Foi utilizado o seguinte modelo matemático: $Y_{i j}=m+T_{i}+E_{i j}$, em que, $\mathrm{Y}_{\mathrm{ij}}$ representa a variável dependente; $\mathrm{i}=$ o índice de tratamentos; $\mathrm{j}=\mathrm{o}$ índice de repetições; $m$ é a média de todas as observações; $\mathrm{T}_{\mathrm{i}}$ corresponde ao efeito dos tratamentos; $E_{i j}$ é $o$ erro experimental.

\section{RESULTADOS E DISCUSSÃO}

Com relação à experimentação in vitro (Tabela 1), observa-se que houve efeito $(\mathrm{P}<0,05)$ do óleo mineral sobre a eclodibilidade de larvas a partir da solução constituída por $5 \%$, embora esse nível não tenha diferido de $50 \%$ de óleo e do grupo testemunha (sem óleo), indicando que os resultados foram irregulares. Os melhores resultados foram obtidos com os níveis de 10 e $20 \%$ de concentração; considerando o tratamento com $100 \%$ de óleo mineral, não houve eclodibilidade. Para eficácia, os valores são baixos até o nível de $5 \%$ de concentração; para os demais tratamentos, os valores são elevados e associados ao nível de óleo utilizado. Esses resultados são atribuídos ao processo de asfixia que o óleo causa no carrapato através do bloqueio de suas aberturas superficiais (espiráculos), responsáveis pela respiração (GUIRADO et al., 2003).

Para o óleo de citronela, observa-se que houve efeito $(\mathrm{P}<0,05)$ a partir de $1 \%$ de óleo, sobre a eclodibilidade das larvas. Para a solução feita com $0,5 \%$ de óleo de citronela, não houve diferença em relação ao grupo controle. Não houve eclodibilidade com níveis de concentração elevada de óleo (50 e 100\%). Os dados submetidos à análise de regressão demonstram efeito descendente $\mathrm{y}=82,265$ $-3,505 \mathrm{x}+0,027 \mathrm{x}^{2} ; \mathrm{R}^{2}=0,87 ; \mathrm{P}=0,0144$, para eclodibilidade à medida que se aumenta a concentração do óleo de citronela nas soluções. Resultados semelhantes foram obtidos em pesquisa feita com o mesmo óleo, encontrando-se eclodibilidade de $25 \%$ com solução constituída por $5 \%$ de óleo; com $10 \%$ de óleo não houve eclodibilidade (MARTINS, 2006).

Para eficácia, houve efeito $(\mathrm{P}<0,05)$ a partir da solução constituída com menor nível de óleo de citronela $(0,5 \%)$. A partir de 5\% de óleo de citronela, a eficácia foi superior a $80 \%$. Os dados submetidos à análise de regressão demonstram efeito quadrático com início ascendente $\mathrm{y}=27,215+13,921 \mathrm{x}-$ $0,701 \mathrm{x}^{2} ; \quad \mathrm{R}^{2}=0,98 ; \quad \mathrm{P}=0,0023 . \quad \mathrm{Em}$ pesquisas conduzidas com o mesmo produto foram observados resultados similares, com $100 \%$ de eficácia a partir 
de soluções contendo $10 \%$ de óleo de citronela (MARINS, 2006). Resultados bem inferiores foram encontrados em concentração de $20 \%$ de óleo de citronela (C. nardus), com eficácia de $17 \%$ (COSTA et al., 2008).

Tabela1. Médias porcentuais de eclodibilidade de larvas e da eficácia acaricida das soluções constituídas por diferentes concentrações de óleo mineral e óleo de citronela (Cymbopogon winterianus Jowitt) aplicado sobre teleóginas de Rhipicephalus (Boophilus) microplus pelo teste de imersão de fêmeas ingurgitadas. Santa Maria, RS, 2011

\begin{tabular}{lcccc}
\hline \multirow{2}{*}{ Níveis de óleo (\%) } & \multicolumn{2}{c}{ Eclosão (\%) } & \multicolumn{2}{c}{ Eficácia do produto (\%) } \\
\cline { 2 - 5 } & $\begin{array}{c}\text { Óleo } \\
\text { mineral }\end{array}$ & $\begin{array}{c}\text { Óleo de } \\
\text { citronela }\end{array}$ & $\begin{array}{c}\text { Óleo } \\
\text { mineral }\end{array}$ & $\begin{array}{c}\text { Óleo de } \\
\text { citronela }\end{array}$ \\
\hline 0,0 (controle) & $98,5^{\mathrm{a}}$ & $96,5^{\mathrm{a}}$ & $0,0^{\mathrm{f}}$ & $0,0^{\mathrm{e}}$ \\
0,5 & $100,0^{\mathrm{a}}$ & $99,5^{\mathrm{a}}$ & $1,0^{\mathrm{f}}$ & $34,5^{\mathrm{d}}$ \\
1,0 & $100,0^{\mathrm{a}}$ & $82,0^{\mathrm{c}}$ & $7,5^{\mathrm{e}}$ & $43,0^{\mathrm{de}}$ \\
2,0 & $98,5^{\mathrm{a}}$ & $91,0^{\mathrm{b}}$ & $0,0^{\mathrm{f}}$ & $48,0^{\mathrm{c}}$ \\
5,0 & $98,0^{\mathrm{ab}}$ & $50,0^{\mathrm{d}}$ & $0,5^{\mathrm{f}}$ & $82,0^{\mathrm{b}}$ \\
10,0 & $90,5^{\mathrm{c}}$ & $5,5^{\mathrm{f}}$ & $30,5^{\mathrm{d}}$ & $99,0^{\mathrm{a}}$ \\
20,0 & $93,5^{\mathrm{bc}}$ & $11,5^{\mathrm{e}}$ & $33,5^{\mathrm{c}}$ & $99,0^{\mathrm{a}}$ \\
50,0 & $97,5^{\mathrm{ab}}$ & $0,0^{\mathrm{f}}$ & $71,0^{\mathrm{b}}$ & $100,0^{\mathrm{a}}$ \\
100,0 & $0,0^{\mathrm{d}}$ & $0,0^{\mathrm{f}}$ & $100,0^{\mathrm{a}}$ & $100,0^{\mathrm{a}}$ \\
CV $(\%)$ & 1,36 & 3,07 & 1,77 & 3,37 \\
\hline
\end{tabular}

Médias com letras distintas, na coluna, indicam diferença significativa $(\mathrm{P}<0,05)$ pelo teste de Tukey. Óleo de citronela oriundo do Laboratório de Óleos Essenciais (UNIJUÍ - Ijuí, RS), do Polo Oleoquímico de Três Passos, RS. CV= Coeficiente de variação.

Resultados obtidos com avaliações in vitro com $3 \%$ de óleo de citronela (C. nardus), mediante três aplicações de $1 \%$ em três dias consecutivos, em dois experimentos, nos quais foram avaliados produtos de origem distinta, verificaram-se eficácias de 79,3 e de 92,1\% (OLIVO et al., 2008). Também em pesquisa em que se utilizou óleo de citronela a 12,5; 8,3 e 7,1\% diluído em etanol foi observada ação larvicida de 95,$7 ; 92,7$ e $58,1 \%$, respectivamente (CHUNGSAMARNYART $\&$ JIWAJINDA, 1992).

A ação acaricida do óleo de citronela deve-se, provavelmente, ao princípio ativo citronelal (CHAGAS, 2004), que é o principal componente desse produto. Já Martins (2006), avaliando os principais constituintes deste óleo (citronelal, geraniol e citronelol), sobre a ação acaricida, larvicida, de inibição da postura e eclodibilidade, verificou que o citronelal e o geraniol apresentam ação superior em relação ao citronelol. $\mathrm{O}$ autor apontou também para uma possível ação carrapaticida a partir do efeito sinérgico dos distintos componentes do óleo. Trabalho realizado por Enan (2005) demonstrou que entre a principal ação inseticida de diferentes constituintes de óleos essenciais incluindo o citronelal está no bloqueio dos receptores de octopamina (que possui ação neurotransmissora, neuromoduladora e como neurohormônio). A falta de receptores de octopamina nos vertebrados contribui para a seletividade dos óleos essenciais como inseticidas, pois são tóxicos para os insetos, mas não os são para os mamíferos (ENAN, 2005). 
Para a ação acaricida in vivo (Figura 1), observa-se que a eficácia do produto químico foi mais rápida, correspondendo em $100 \%$ no $3^{\circ}$ dia pós-tratamento. Para a solução feita com o fitoterápico, houve eficácia de $96,6 \%$ no $14^{\circ}$ dia póstratamento. $\mathrm{Na}$ avaliação feita no $21^{\mathrm{o}}$ dia, observa-se que a eficácia com óleo de citronela manteve-se próxima de $90 \%$, enquanto a solução com amitraz foi de $46,5 \%$. Esse resultado demonstra que o óleo de citronela também age sobre as formas imaturas do carrapato, diferentemente do amitraz que tem menor ação sobre elas (Heimerdinger et al., 2006).

Comparativamente, observa-se que a solução constituída pelo óleo de citronela a 8,6\% apresenta desempenho efetivo em controlar a infestação de carrapatos se comparada com o produto químico. Os resultados também apontam que houve associação entre a eficácia obtida in vitro, de $95 \%$ (para o nível estimado de $8,6 \%$ de óleo de citronela, mediante análise de regressão), com valor verificado in vivo, obtendo-se controle próximo a $90 \%$ a partir do $7^{\circ}$ dia pós-banho.

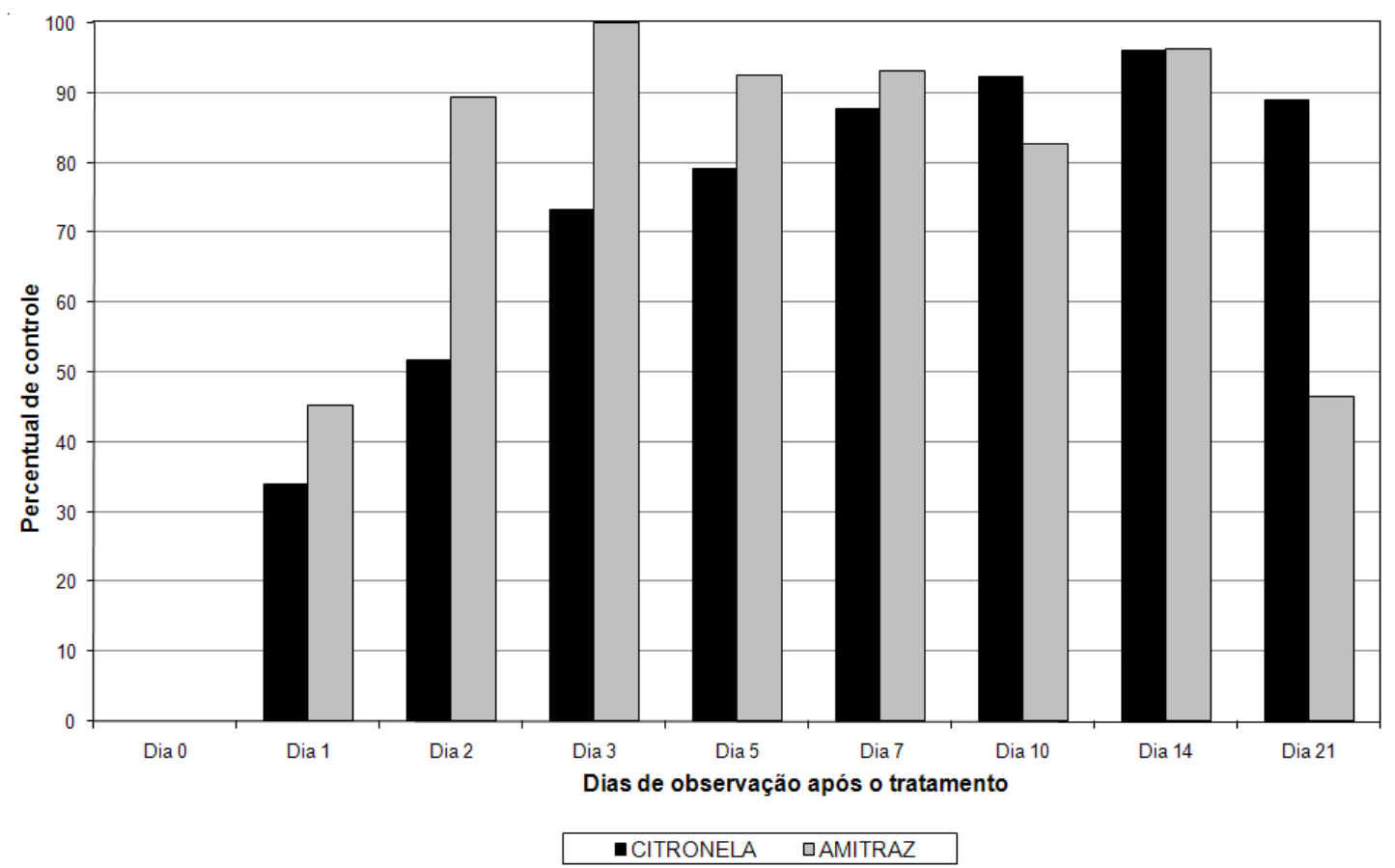

Figura 1. Efeito acaricida da solução aquosa contendo óleo de citronela (Cymbopogon winterianus Jowitt) e do amitraz contra o carrapato Rhipicephalus (Boophilus) microplus em bovinos da raça Holandesa. Santa Maria, RS, 2011

Avaliações feitas in vivo, usando óleo de citronela, mas de outra espécie $(C$. nardus), nas quais foram usadas soluções com 3 e $4 \%$ de óleo, a eficácia foi de 22,5 e $39,1 \%$ após 14 dias de avaliação (AGNOLIN et al., 2010) confirmam os resultados obtidos
(Tabela 1) da ação parcial do óleo com níveis de inclusão menores do que $5 \%$. Os resultados verificados na presente pesquisa são superiores aos obtidos por MARTINS \& GONZÁLEZ (2007), com eficácia de $60 \%$ ao usarem solução 
constituída por $10 \%$ de óleo de citronela (C. winterianus) em etanol.

Para as variáveis fisiológicas não foram observadas diferenças entre os animais do grupo controle e àqueles banhados com a solução constituída por óleo de citronela (Tabela 2). Os valores levantados na avaliação inicial, antecedendo a aplicação do tratamento, às 9:00h, demonstram que os animais apresentavam variáveis fisiológicas próximas da normalidade (SMITH, 1994). Observa-se, no entanto, que nos dois grupos houve elevação dos valores da frequência cardíaca e respiratória, com pico na avaliação feita às 15:00h. Também houve elevação das temperaturas do globo ocular e da pele entre às 12:00 e às 15:00h, comprovando que os animais passaram por períodos de estresse térmico durante o dia.

Tabela 2. Variáveis fisiológicas de vacas da raça Holandesa, submetidas à aplicação de soluções contendo $8,6 \%$ de óleo de citronela (Cymbopogon winterianus Jowitt). Santa Maria, RS, 2011

\begin{tabular}{|c|c|c|c|c|c|}
\hline \multirow[b]{2}{*}{$\begin{array}{l}\text { Período } \\
\text { (hora do } \\
\text { dia) }\end{array}$} & \multirow[b]{2}{*}{ Grupo } & \multicolumn{4}{|c|}{ Variáveis fisiológicas } \\
\hline & & $\begin{array}{c}\text { Frequência } \\
\text { cardíaca } \\
\text { (bat/min.) }\end{array}$ & $\begin{array}{l}\text { Frequência } \\
\text { respiratória } \\
\text { (mov/min.) }\end{array}$ & $\begin{array}{c}\text { Temperatura } \\
\text { globo ocular } \\
\left({ }^{\circ} \mathrm{C}\right)\end{array}$ & $\begin{array}{l}\text { Temperatura } \\
\text { da pele }\left({ }^{\circ} \mathrm{C}\right)\end{array}$ \\
\hline \multirow{2}{*}{$\begin{array}{l}\text { Antes } \\
(9: 00)\end{array}$} & Controle $^{1}$ & 68,0 & 33,3 & 31,3 & 27,0 \\
\hline & Citronela $^{2}$ & 68,0 & 34,6 & 31,3 & 26,0 \\
\hline \multirow{2}{*}{$\begin{array}{l}3 \text { horas } \\
(12: 00)\end{array}$} & Controle & 72,0 & 49,3 & 33,3 & 31,6 \\
\hline & Citronela & 78,6 & 44,0 & 33,6 & 33,0 \\
\hline \multirow{2}{*}{$\begin{array}{l}6 \text { horas } \\
(15: 00)\end{array}$} & Controle & 80,0 & 56,0 & 31,0 & 27,6 \\
\hline & Citronela & 84,0 & 52,0 & 33,3 & 27,3 \\
\hline \multirow{2}{*}{$\begin{array}{l}24 \text { horas } \\
(9: 00)\end{array}$} & Controle & 64,0 & 28,6 & 28,6 & 23,0 \\
\hline & Citronela & 69,3 & 33,3 & 28,3 & 22,3 \\
\hline \multirow{2}{*}{ Média } & Controle & 71,0 & 41,8 & 31,0 & 27,3 \\
\hline & Citronela & 75,0 & 41,0 & 31,1 & 27,1 \\
\hline $\mathrm{CV}(\%)$ & & 15,7 & 41,1 & 6,5 & 14,0 \\
\hline
\end{tabular}

Diferença não significativa $(\mathrm{P}>0,05)$ pelo teste $\mathrm{F} ;{ }^{1}$ Testemunha $=$ grupo controle negativo; ${ }^{2}$ Citronela 8,6 $\%$ = óleo de citronela a 8,6\%; Período = antes da aplicação, às 3 e 6 horas (dia 27/06/2010) e 24 horas após a aplicação (dia 28/06/2010). Temperaturas mínima e máxima de 16 e $28^{\circ} \mathrm{C}$ e de 14 e $21^{\circ} \mathrm{C}$, respectivamente para o dia 27 e 28/06/2010.

Os resultados podem ser importantes como parte da estratégia de controle do carrapato em diferentes sistemas de produção, uma vez que o óleo de citronela demonstrou ter ação efetiva sobre a cepa de carrapato testada. Considerando-se outros óleos essenciais, como o eucalipto (OLIVO et al., 2013), o valor encontrado, de $8,6 \%$ para se atingir eficácia superior a
95\%, e considerado elevado. Diante disso, e levando-se em conta o custo da solução, em sistemas produtivos em que se faz o controle individual dos animais, pode-se aplicar o produto em áreas infestadas, reduzindo, consequentemente, a quantidade de solução utilizada.

Assim, conclui-se que as soluções contendo níveis crescentes de óleo 
Rev. Bras. Saúde Prod. Anim., Salvador, v.15, n.3, p.604-612 jul./set., 2014 http://www.rbspa.ufba.br ISSN 15199940

mineral, exceto com $100 \%$ do produto, apresentam baixa eficácia e elevada variabilidade nas respostas obtidas. Para as soluções contendo níveis crescentes de óleo de citronela, avaliados in vitro, verificou-se eficácia acaricida com efeito quadrático ascendente.

A solução contendo $8,6 \%$ de óleo de citronela apresenta eficácia no controle do carrapato dos bovinos, guardando associação com os níveis avaliados in vitro. Para as variáveis fisiológicas, houve similaridade entre os grupos de animais não tratados e os que foram banhados com solução contendo óleo de citronela.

\section{REFERÊNCIAS}

AGNOLIN, C.A.; OLIVO, C.J.; SANGIONI, L.A.; PARRA, C.L.C.; DIEHL, M.S.; SANTOS, J.C.; AGUIRRE, P.F.; CAMILLO, G.; IRGANG, D.M. Concentrações de óleo de citronela no controle de carrapatos de bovinos. Revista. Brasileira de Agroecologia, v.5, n. 2, p.187-193, 2010.

AMARAL, N.K. Guidelines for the evaluation of ixodicides against the cattle tick Boophilus microplus (Canestrini, 1887) (Acari: ixodidae). Revista Brasileira de Parasitologia Veterinária, v.2, n.2, p.144-151, 1993.

CHAGAS, A.C.S. Controle de parasitas utilizando extratos vegetais. Revista Brasileira de Parasitologia Veterinária, v.13, n.1, p.156-60, 2004.

CHUNGSAMARNYART, N.; JIWAJINDA, S. Acaricidal activity of volatile oil from lemon and citronella grasses on tropical cattle ticks.

Kasetsart Journal: Natural Science, v.26, n.5, p.46-51, 1992.
COSTA, F.B.; VASCONCELOS, P.S.S.; SILVA, A.M.M.; BRANDÃO, V.M.; SILVA, I.A. DA; TEIXEIRA, W.C.; GUERRA, R.M.S.N.; DOS SANTOS, A.C.G. Eficácia de fitoterápicos em fêmeas ingurgitadas de Boophilus microplus, provenientes da mesorregião oeste do Maranhão, Brasil. Revista Brasileira de Parasitologia Veterinária, v.17, p.8386, 2008. Supl.1.

DRUMMOND, R.O.; ERNST, S.E.; TREVINO, J.L.; GLADNEY, W.J.; GRAHAM, O. H. Boophilus annulatus and Boophilus microplus: Laboratory test of insecticides. Jornal of Economic Entomology, v.66, n.1, p.130-133, 1973.

ENAN, E.E. Molecular and pharmacological analysis of an octopamine receptor from American cockroach and fruit fly in response to plant essential oils. Archives of Insect Biochemistry and Physiology, v.59, n.3, p.161-171, 2005.

FARIAS, M.P.O.; SOUSA, D.P.; ARRUDA, A.C.; WANDERLEY, A.G.; TEIXEIRA,W. C.; ALVES, L. C.; FAUSTINO, M. A. G. Potencial acaricida do óleo de andiroba Carapa guianensis Aubl. sobre fêmeas adultas ingurgitadas de Anocentor nitens Neumann, 1897 e Rhipicephalus sanguineus Latreille, 1806. Arquivo Brasileiro de Medicina Veterinária e Zootecnia, v.61, n.4, p.877-882, 2009.

FURLONG, J.; MARTINS, J.R.; PRATA, M. Controle estratégico do carrapato dos bovinos. A Hora Veterinária, v.23, n.137, p.53-56, 2004.

GOMES, A.; KOLLER, W.W.; BARROS, A.T.M. Suscetibilidade de Rhipicephalus (Boophilus) microplus a 
Rev. Bras. Saúde Prod. Anim., Salvador, v.15, n.3, p.604-612 jul./set., 2014 http://www.rbspa.ufba.br ISSN 15199940

carrapaticidas em Mato Grosso do Sul, Brasil. Ciência Rural, v.41, n.8, p.1447-1452, 2011.

GUIRADO, N.; AMBROSANO, E.J.; ARÉVALO, R.A.; ROSSI, F.; MENDES, P.C. D.; AMBROSANO, G. M. B. Controle da cochonilha EscamaFarinha em citros com uso de óleos em pulverização. Laranja, v.24, n.2, p.329335, 2003.

HEIMERDINGER, A.; OLIVO, C.J.; MOLENTO, M.B; AGNOLIN, C.A.; ZIECH, M. F.; SCARAVELLI, L.F. B.; SKONIESKI, F.R.; BOTH, J.F.;

CHARÃO, P. Extrato alcoólico de capim-cidreira no controle do Boophilus microplus em bovinos. Revista

Brasileira de Parasitologia

Veterinária, v.15, n.1, p.37-39, 2006.

KLAFKE, G.M.; SABATINI, G.A. de; ALBUQUERQUE, T.A.; MARTINS, J.R.; KEMP, D.H.; ILLER, R.J.;

SCHUMAKER, T.T. Larval immersion tests with ivermectin in populations of the cattle tick Rhipicephalus (Boophilus) microplus (Acari: Ixodidae) from State of Sao Paulo, Brazil. Veterinary

Parasitology, v.142, n.3-4, p.386-390, 2006.

MARTINS, R.M. Estudo "in vitro" da ação acaricida do óleo essencial da gramínea Citronela de Java (Cymbopogon winterianus Jowitt) no carrapato Boophilus microplus. Revista Brasileira de Plantas Medicinais, v.8, n.2, p.71-78, 2006.

MARTINS, R.M.; GONZÁLEZ, F.H.D. Uso del aceite de citronela de Java (Cymbopogon winterianus Jowitt (Panicoidideae) como acaricida frente a la garrapata Boophilus microplus Canestrini (Acari: Ixodidae). Revista Brasileira de Plantas Medicinais, v.9, n.4, p.1-8, 2007.
OLIVO, C.J.; AGNOLIN, C.A.; PARRA, C.L.C.; VOGEL, F.S.F.; RICHARDS, N. S.P.S.; PELLEGRINI, L.G.; WEBE, A.; PIVOTO, F.; ARAUJO, L. Efeito do óleo de eucalipto (Corymbia citriodora) no controle do carrapato bovino. Ciência. Rural, v.43, n.2, p.331-337, 2013.

OLIVO, C.J.; CARVALHO, N.M.; SILVA, J.H.S.; VOGEL, F.F.; MASSARIOL, P.; MEINERZ, G.; AGNOLIN, C.A.; MOREL, A.F.; VIAU, L.V. Óleo de citronela no controle do carrapato de bovinos. Ciência. Rural, v.38, n.2, p.406-410, 2008.

PARIZI, L.F.; POHL, P.C.; MASUDA, A.; VAZ JUNIOR, I.S. New approaches toward antiRhipicephalus (Boophilus) microplus tick vaccine. Revista Brasileira de Parasitologia Veterinária, v.18, n.1, p.1-7, 2009.

SMITH, B.P. Tratado de medicina interna de grandes animais. 2.ed. São Paulo: Manole, 1994. 1738p.

WHARTON, R.H.; UTECH, K.B.W. The relation between engorgement and dropping of Boophilus microplus (Canestrine) (Ixodiadae) to the assessment of tick numbers on cattle.

Journal of the Australian Entomological Society, v.9, p.171182, 1970.

Data de recebimento: 30/01/2014

Data de aprovação: 11/08/2014 